\title{
Effects of fullerene encapsulation on structure and photophysical properties of porphyrin-linked single-walled carbon nanotubes.
}

\section{$\operatorname{AUTHOR}(\mathrm{S}):$}

Umeyama, Tomokazu; Mihara, Junya; Hayashi, Hironobu; Kadota, Naoki; Chukharev, Vladimir; Tkachenko, Nikolai V; Lemmtyinen, Helge; Yoshida, Kaname; Isoda, Seiji; Imahori, Hirohi

\section{CITATION:}

Umeyama, Tomokazu ...[et al]. Effects of fullerene encapsulation on structure and photophysical properties of porphyrin-linked single-walled carbon nanotubes.. Chemical communications 2011, 47(42): 11781-11783

\section{ISSUE DATE:}

2011-09-21

\section{URL:}

http://hdl.handle.net/2433/162896

\section{RIGHT:}

(c) The Royal Society of Chemistry; この論文は出版社版でありません。 引用の際には出版社版をご確認ご利用ください。; This is not the published version. Please cite only the published version. 


\title{
Effects of Fullerene Encapsulation on Structure and Photophysical Properties of Porphyrin-Linked Single-Walled Carbon Nanotubes
}

\author{
Tomokazu Umeyama, ${ }^{a, b}$ Junya Mihara, ${ }^{a}$ Hironobu Hayashi, ${ }^{a}$ Naoki Kadota, ${ }^{a}$ Vladimir Chukharev, ${ }^{c}$ \\ Nikolai V. Tkachenko, ${ }^{* c}{ }^{c}$ Helge Lemmtyinen, ${ }^{c}$ Kaname Yoshida, ${ }^{d}$ Seiji Isoda ${ }^{e}$ and Hirohi Imahori ${ }^{* a, e, f}$ \\ ${ }_{5}$ Received (in $\left.X X X, X X X\right)$ Xth $X X X X X X X X X 20 X X$, Accepted $X$ th $X X X X X X X X X 20 X X$ \\ DOI: 10.1039/b000000x
}

Fullerene-encapsulating single-walled carbon nanotubes $\left(\mathrm{C}_{60} @ \mathrm{SWNT}\right)$ linked with porphyrins by a short bridge have been prepared for the first time. Steady state and timeresolved spectroscopies demonstrated the initial formation of an exciplex state, followed by a charge-separated state.

Because of the exceptional electronic, optical, and mechanical properties, single-walled carbon nanotubes (SWNT) have been explored as promising building blocks for artificial ${ }_{15}$ photosynthesis and photovoltaic devices. ${ }^{1}$ Consequently, functionalizations of SWNT with photoactive molecules for the study of their excited state dynamics have become an active area of researches. ${ }^{2-6}$ Among the photoactive components, porphyrins are stable electron-donors with a 20 large extinction coefficient in the visible region and thereby have been widely employed in combination with SWNT. ${ }^{2,3}$ Photophysical investigation on various noncovalently assembled porphyrin-SWNT hybrids, e.g., using $\pi-\pi$ stacking and ionic interactions, by steady-state and time-resolved 25 spectroscopic measurements has revealed the occurrence of electron transfer from the excited porphyrins to the SWNT. ${ }^{2}$ In addition, porphyrin-SWNT composites covalently-linked by a flexible bridge have also shown photoinduced charge separation between the porphyrin and SWNT. ${ }^{3}$ On the other 30 hand, we proposed the evolution of an exciplex between porphyrin and SWNT when the two components were tethered by a short rigid phenylene spacer. ${ }^{6}$ Photoelectrochemical measurements suggested that the exciplex decays directly to

\footnotetext{
$\overline{{ }^{a} \text { Department of Molecular Engineering, Graduate School of Engineering, }}$ Kyoto University, Nishikyo-ku, Kyoto 615-8510, Japan

${ }^{b}$ PRESTO, Japan Science and Technology Agency (JST), 4-1-8 Honcho, Kawaguchi, Saitama 332-0012, Japan

${ }^{c}$ Department of Chemistry and Bioengineering, Tampere University of Technology, P.O. Box 541, FIN-33101 Tampere, Finland

${ }^{d}$ Institute for Chemical Research, Kyoto University, Uji, Kyoto 611-0011, Japan

${ }^{e}$ Institute for Integrated Cell-Material Sciences (iCeMS), Kyoto

University, Nishikyo-ku, Kyoto 615-8510, Japan

${ }^{f}$ Fukui Institute for Fundamental Chemistry, Kyoto University, TakanoNishihiraki 34-4, Sakyo-ku, Kyoto 606-8103, Japan. Fax: +8175383

2571; Tel: +81 75383 2566; E-mail: imahori@scl.kyoto-u.ac.jp

\$ This article is part of the ChemComm 'Artificial photosynthesis' web themed issue.

$\dagger$ Electronic Supplementary Information (ESI) available: Experimental details and spectroscopic and microscopic data. See DOI: $10.1039 / \mathrm{b} 000000 \mathrm{x} /$
}

the ground state without generating the charge-separated ${ }_{35}$ state. $^{6}$ Therefore, the separation distance and spatial orientation between porphyrin and SWNT are crucial factors to control the relaxation processes from the excited states.

One of the fundamental approaches for controlling the electronic properties of SWNT is the inner space doping of ${ }_{40}$ suitable-sized organic molecules like fullerenes. ${ }^{7}$ It is known that encapsulated fullerenes cause changes in the Fermi levels and band gap energies of SWNT. ${ }^{8}$ When a suitable donor is combined with fullerene-encapsulated SWNT, i.e., fullerene peapods or $\mathrm{C}_{60} @ \mathrm{SWNT}$, the enhanced electron-accepting 45 character due to the ground state charge transfer (CT) interaction between $\mathrm{C}_{60}$ and SWNT can be supposed to promote the electron transfer from the excited donor molecule to the fullerene peapod. ${ }^{9}$ Despite such intriguing properties of fullerene peapods, ternary nanohybrids of fullerene peapods 50 with large $\pi$-aromatic molecules have yet to be prepared. As such, interactions between covalently linked peapods and large $\pi$-aromatic molecules in the ground and excited states have never been investigated. Herein, we report the first preparation and photophysical properties of fullerene peapods ${ }_{55}$ covalently functionalized ${ }^{10}$ with porphyrins. To evaluate the effects of the fullerene encapsulation on the structure and photophysical properties, we chose the same short rigid phenylene spacer as that employed for the porphyrin-SWNT reference without $\mathrm{C}_{60}$ molecules. ${ }^{6}$

${ }_{60}$ Encapsulation of $\mathrm{C}_{60}$ into open-ended SWNT (p-SWNT) with diameters of $1.3-1.6 \mathrm{~nm}$ was conducted by sublimation method (Fig. S1 in ESI). ${ }^{5 \mathrm{a}, 7 \mathrm{~b}}$ Then, zinc porphyrin-linked fullerene peapod, $\mathrm{C}_{60} @ \mathrm{SWNT}-\mathrm{ZnP}$, was synthesized according to the two-step functionalization procedure as ${ }_{65}$ shown in Scheme 1 (see Experimental in ESI). ${ }^{11}$ Briefly, surfactant-wrapped $\mathrm{C}_{60} @ \mathrm{SWNT}$ was reacted with $p$ iodophenyl diazonium salt in aqueous solution, followed by treatment with the in-situ generated diazonium salt in $o$ dichlorobenzene (ODCB) to yield pre-functionalized peapod 70 with $p$-iodophenyl groups $\left(\mathrm{C}_{60} @ \mathrm{SWNT}-\mathrm{PhI}\right)$. Then, Suzuki coupling reaction of $\mathrm{C}_{60} @ \mathrm{SWNT}-\mathrm{PhI}$ with porphyrin boronic ester gave $\mathrm{C}_{60} @ \mathrm{SWNT}-\mathrm{ZnP}$. Transmission electron microscopy (TEM) measurements verified that the inner space of SWNT was still well-packed by the encapsulated $\mathrm{C}_{60}$ 75 molecules after the modification of outer skeleton in the intensive conditions (Fig. S2 in ESI). Both $\mathrm{C}_{60} @ \mathrm{SWNT}-\mathrm{PhI}$ 
and $\mathrm{C}_{60} @ \mathrm{SWNT}-\mathrm{ZnP}$ exhibited high solubility in common organic solvents including $N, N$-dimethylformamide (DMF), ODCB and toluene. The atomic force microscopy (AFM) image of $\mathrm{C}_{60} @ \mathrm{SWNT}-\mathrm{ZnP}$ spin-coated on mica from DMF 5 dispersion (Fig. S3 in ESI) revealed fibrous structures with an average diameter of $4.5 \pm 1 \mathrm{~nm}$, implying efficient debundling of $\mathrm{C}_{60} @ \mathrm{SWNT}$ by the bulky ZnP units.

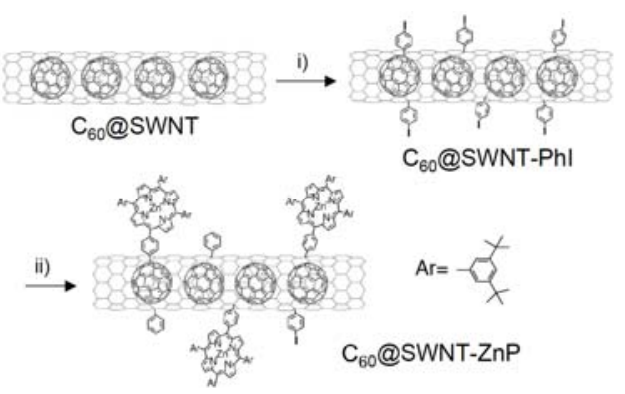

${ }_{10}$ Scheme 1. Preparation of $\mathrm{C}_{60} @ \mathrm{SWNT}-\mathrm{ZnP}$. i) 4-Iodobenzenediazonium tetrafluoroborate, $\mathrm{SDBS}, \mathrm{H}_{2} \mathrm{O}$, room temperature, $2 \mathrm{~h}$, then $p$-iodoaniline, isopentyl nitrite, ODCB, $65{ }^{\circ} \mathrm{C}, 4 \mathrm{~h}$; ii) 5(pinacolboryl)-10,15,20-tris(3,5-di-tert-butylphenyl)porphyrinato zinc(II), $\mathrm{Pd}\left(\mathrm{PPh}_{3}\right)_{4}, \mathrm{Cs}_{2} \mathrm{CO}_{3}, \mathrm{DMF}, 105^{\circ} \mathrm{C}, 24 \mathrm{~h}$.

X-ray photoelectron spectroscopy (XPS) measurements corroborated the covalent functionalizations of $\mathrm{C}_{60} @ \mathrm{SWNT}$ (Fig. S4 in ESI). The functionalization ratio of $\mathrm{C}_{60} @ \mathrm{SWNT}$ $\mathrm{ZnP}$ was estimated to be one $\mathrm{ZnP}$ unit per 300 carbons of 20 nanotube sidewall (details of the estimation are in ESI). This corresponds to one $\mathrm{ZnP}$ unit at each nanotube length of 3 - 4 $\mathrm{nm}$. Taking into account a size of the porphyrin $(1.8 \mathrm{~nm}, \mathrm{Fig}$. S5 in ESI), the ZnP molecules would not interact directly with each other on the peapod. Moreover, the same two-step

${ }_{25}$ functionalization using $\mathrm{p}$-SWNT yielded p-SWNT-ZnP with the functionalization ratio of one $\mathrm{ZnP}$ unit per 400 sidewall carbons (Fig. S4), which largely agrees with the ratio of $\mathrm{C}_{60} @$ SWNT-ZnP. The influence of the $\mathrm{C}_{60}$ encapsulation on the sidewall reactivity was not significant. Resonant Raman 30 spectra of $\quad \mathrm{C}_{60} @$ SWNT-ZnP, $\quad \mathrm{C}_{60} @$ SWNT-PhI, and $\mathrm{C}_{60} @ \mathrm{SWNT}$ also support the surface modification on the $\mathrm{C}_{60} @ \mathrm{SWNT}$ (Fig. S6 in ESI).

Fig. 1a displays UV-vis absorption spectra of $\mathrm{C}_{60} @$ SWNT-ZnP, $\mathrm{C}_{60} @ \mathrm{SWNT}-\mathrm{PhI}$, and 5-phenyl-10,15,2035 tris(3,5-di-tert-butylphenyl)porphyrinatozinc(II) (ZnP-ref) in DMF. $C_{60} @ S W N T-Z n P$ exhibits a moderate Soret band at around $428 \mathrm{~nm}$ and weak Q bands at around 560 and $599 \mathrm{~nm}$, in addition to the broad structureless absorption of the $\mathrm{C}_{60} @ \mathrm{SWNT}$ extending into the NIR region. This provides 40 unambiguous evidence for the presence of the $\mathrm{ZnP}$ on the $\mathrm{C}_{60} @ \mathrm{SWNT}$. The Soret band of $\mathrm{C}_{60} @ \mathrm{SWNT}-\mathrm{ZnP}$ was broadened and red-shifted by $425 \mathrm{~nm}$ compared with that of ZnP-ref, suggesting that there is weak electronic communication between the $\mathrm{ZnP}$ and $\mathrm{C}_{60} @ \mathrm{SWNT}$ in the 45 ground state. Upon excitation of $\mathrm{C}_{60} @ \mathrm{SWNT}-\mathrm{ZnP}$ and ZnPref at the Soret band, where the absorbance of the porphyrin was adjusted to be identical, the emission intensity from the $\mathrm{ZnP}$ unit on the $\mathrm{C}_{60} @ \mathrm{SWNT}$ decreased drastically relative to that of ZnP-ref (Fig. 1b). Such efficient quenching of the ${ }_{50}$ porphyrin excited singlet state $\left({ }^{1} \mathrm{ZnP}^{*}\right)$ is indicative of a strong interaction between the ${ }^{1} \mathrm{ZnP}^{*}$ and $\mathrm{C}_{60} @ \mathrm{SWNT}$. Note here that analogous absorption broadening and fluorescence quenching were also observed in the spectra of p-SWNT-ZnP (Fig. S7 in ESI). ${ }^{6}$

55
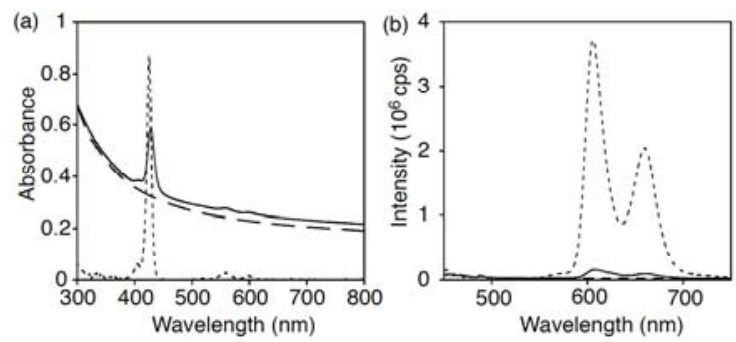

Fig. 1. (a) UV-vis absorption and (b) fluorescence spectra of $\mathrm{C}_{60} @ \mathrm{SWNT}-\mathrm{ZnP}$ (solid line), $\mathrm{C}_{60} @ \mathrm{SWNT}-\mathrm{PhI}$ (dashed line), and ZnP-ref (1.6 $\mu \mathrm{M}$ for (a) and $0.3 \mu \mathrm{M}$ for (b), dotted line) in DMF. ${ }_{60}$ For the excitation, the absorbance of the porphyrin moiety was adjusted to be identical at the peak position of the Soret band.

To get insights into the interaction in the excited state, we monitored the porphyrin emission decays of $\mathrm{C}_{60} @ \mathrm{SWNT}-\mathrm{ZnP}$ ${ }_{65}$ and ZnP-ref by time-correlated single-photon counting (TCSPC) technique (Table S1 in ESI). The fluorescence decay of ZnP-ref was analyzed by a single component with a lifetime $(\tau)$ of $2.0 \mathrm{~ns}$, which is in good agreement with the literature value reported for analogous zinc tetraphenyl70 porphyrins. ${ }^{12}$ On the other hand, the fluorescence decay curve of $\mathrm{C}_{60} @ \mathrm{SWNT}-\mathrm{ZnP}$ was fitted by a fast major component ( $\tau<$ $70 \mathrm{ps}$ ) and a slow minor component ( $\tau=1.9 \mathrm{~ns}$ ). These imply the occurrence of ultrafast quenching of ${ }^{1} \mathrm{ZnP} *$ by the $\mathrm{C}_{60} @ \mathrm{SWNT}$, which is beyond the time resolution of the 75 present TCSPC system (ca. $70 \mathrm{ps}$ ). The minor component may stem from the impurity or degradation of $\mathrm{C}_{60} @$ SWNT-ZnP during the measurement. Similar quenching of ${ }^{1} \mathrm{ZnP}^{*}$ was also seen in the spectrum of p-SWNT-ZnP (Table S1). ${ }^{6}$

To shed light on the ultrafast process, the femtosecond 80 pump-probe transient absorption measurements were performed for p-SWNT-ZnP, p-SWNT-PhI, C 60 @SWNT-ZnP and $\mathrm{C}_{60} @$ SWNT-PhI with a laser excitation at $420 \mathrm{~nm}$ where both the $\mathrm{ZnP}$ and the nanotube moieties were excited. Transient absorption component spectra of p-SWNT-ZnP 85 showed negative signal in the full range of the measurement $(500-1100 \mathrm{~nm})$ with a lifetime $(\tau)$ of 0.3 ps (Fig. S8 in ESI). This signal can be assigned to the ground state photobleaching due to the SWNT absorptions of $\mathrm{M}_{11}$ (the lowest transitions between van Hove singularities in the valence and conduction 90 bands of metallic SWNT) and $\mathrm{S}_{22}$ (the second lowest transitions in semiconducting SWNT). ${ }^{13,14}$ The spectrum of $\mathrm{p}$ SWNT-PhI also exhibited similar negative signal (Fig. S8). Additionally, a broad and featureless positive absorption band in the visible region emerged in the spectra of p-SWNT-ZnP ${ }_{95}$ with $\tau$ of $>1 \mathrm{~ns}$. We have already shown that the photoelectrochemical device based on similar porphyrin-SWNT composites linked by the same phenylene spacer revealed no photocurrent response by the porphyrin absorption, ruling out the possibilities of electron and energy transfer from the 100 excited porphyrin to the SWNT. ${ }^{6}$ Therefore, this broad and featureless absorption in the visible region can be assigned to 
the exciplex state comprised of the $\mathrm{ZnP}$ and SWNT. ${ }^{15}$

The absorption changes recorded upon the excitation of $\mathrm{C}_{60} @$ SWNT-ZnP at $420 \mathrm{~nm}$ (Fig. 2 and Fig. S9 in ESI) differ from those of p-SWNT-ZnP. In addition to the negative signal 5 of the ground state photobleaching of the $\mathrm{C}_{60} @ \mathrm{SWNT}$ moiety (Fig. S10 in ESI), the exciplex absorption appeared, but the lifetime ( $\tau=24 \mathrm{ps}$ ) was much shorter than that of p-SWNT$\mathrm{ZnP}$ ( $\tau=1073 \mathrm{ps}$ ). Furthermore, an additional long-lived component $(\tau>2 \mathrm{~ns}$ ) with two minima at 560 and $600 \mathrm{~nm}$ 10 emerged (Fig. S11 in ESI). Importantly, the third component exhibited weak positive absorption in the $650-750 \mathrm{~nm}$ region. Considering the similarity between this band and that of oneelectron oxidized $\mathrm{ZnP},{ }^{12}$ we can assign it as the chargeseparated state. In contrast with p-SWNT-ZnP, where the 15 resultant exciplex decayed without forming the chargeseparated state, $\mathrm{C}_{60} @ \mathrm{SWNT}-\mathrm{ZnP}$ evolves to the porphyrin radical cation and the radical anion of the fullerene peapod after the exciplex formation. The energy level of the chargeseparated state would become lower than that of the exciplex 20 state by the inclusion of the fullerene molecules. It should be noted here that no clear signals for $\mathrm{C}_{60}$ radical anion at 1080 $\mathrm{nm}^{16}$ are visible. This may be rationalized by no occurrence of the consecutive electron transfer from exterior frame of SWNT to the encapsulated $\mathrm{C}_{60}$ or low molar absorption 25 coefficient of $\mathrm{C}_{60}$ radical anion at $1080 \mathrm{~nm}$. The differences in the photodynamics of $\mathrm{C}_{60} @ \mathrm{SWNT}-\mathrm{ZnP}$ and p-SWNT-ZnP highlight the effect of fullerene encapsulation on the electronic communications between the SWNT and ZnP in the excited state.

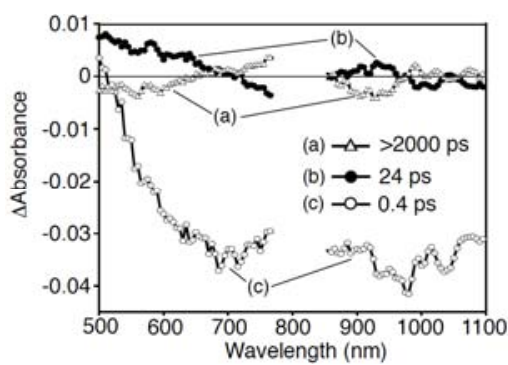

Fig. 2. Spectra of decay components obtained by threeexponential global fit of the transient absorption data of $\mathrm{C}_{60} @$ SWNT-ZnP in DMF. The sample was excited at $420 \mathrm{~nm}$ The fitted time constants are displayed in the figure.

In summary, we have prepared a porphyrin- $\mathrm{C}_{60} @ \mathrm{SWNT}$ composite covalently fixed with a short rigid phenylene spacer for the first time. The porphyrin- $\mathrm{C}_{60} @ \mathrm{SWNT}$ ternary composite disclosed the initial formation of the exciplex state ${ }_{40}$ prior to the charge-separated state, whereas the porphyrinSWNT binary composite with the same phenylene spacer revealed the formation of the exciplex state solely. Our results exemplify that the encapsulation of $\mathrm{C}_{60}$ into SWNT inner space have large impacts on the excited-state interactions 45 between porphyrin and SWNT. These results obtained here demonstrate that the inner space doping of SWNT will have considerable merit for tuning the electronic properties of SWNT in the hybrid materials with photoactive molecules for the applications in artificial photosynthesis and solar energy 50 conversion.
This work is supported by Grant-in-Aid from Specific Area Research, MEXT, Japan (Carbon Nanotube Nano-Electronics) and Strategic Japanese-Finnish Cooperative Program (JST, Tekes and AF). SWNT used in this study was supplied by ${ }_{55}$ Nikkiso Co., Ltd.

\section{Notes and references}

1 (a) F. D'Souza, A. S. D. Sandanakaya and O. Ito, J. Phys. Chem. Lett., 2010, 1, 2856; (b) V. Sgobba and D. M. Guldi, Chem. Soc. Rev., 2009, 38, 165; (c) S. Fukuzumi and T. Kojima, Chem. Mater., 2008,

60 18, 1427; (d) T. Umeyma and H. Imahori, Ener. Environ. Sci., 2008, 1, 120; (e) P. V. Kamat, J. Phys. Chem. C, 2007, 111, 2834.

2 (a) E. Maligaspe, A. S. D. Sandanayaka, T. Hasobe, O. Ito and F. D'Souza, J. Am. Chem. Soc., 2010, 132, 8158; (b) T. Hasobe, S. Fukuzumi and P. V. Kamat, J. Phys. Chem. C, 2006, 110, 25477; (c) 65 C. Ehli, G. M. A. Rahman, N. Jux, D. Balbinot, D. M. Guldi, F. Paolucci, M. Marcaccio, D. Paolucci, M. Melle-Franco, F. Zerbetto, S. Campidelli and M. Prato, J. Am. Chem. Soc., 2006, 128, 11222; (d) M. Alvaro, P. Atienzar, P. de la Cruz, J. L. Delgardo, V. Troiani, H. Garcia, F. Langa, A. Palkar and L. Echegoyen, J. Am. Chem. Soc., 2006, 128, 6626.

3 (a) T. Arai, S. Nobukuni, A. S. D. Sandanayaka and O. Ito, J. Phys. Chem. C, 2009, 113, 14493; (b) T. Palacin, H. L. Khanh, B. Jousselme, P. Jegou, A. Filoramo, C. Ehli, D. M. Guldi and S. Campidelli, J. Am. Chem. Soc., 2009, 131, 15394; (c) S. Campidelli, 75 C. Sooambar, E. L. Diz, C. Ehli, D. M. Guldi and M. Prato, J. Am. Chem. Soc., 2006, 128, 12544.

4 (a) G. Bottari, J. A. Suanzes, O. Trukhina and T. Torres, J. Phys. Chem. Lett., 2011, 2, 905; (b) G. Bottari, G. de la Torre, D. M. Guldi and T. Torres, Chem. Rev., 2010, 110, 6768; (c) M. Á. Herranz, N. 80 Martín, S. Campidelli, M. Prato, G. Brehm and D. M. Guldi, Angew. Cheem. Int. Ed., 2006, 45, 4478.

5 (a) N. Tezuka, T. Umeyama, Y. Matano, T. Shishido, K. Yoshida, T. Ogawa, S. Isoda, K. Stranius, V. Chukharev, N. V. Tkachenko, H. Lemmetyinend and H. Imahori, Energy Environ. Sci., 2011, 4, 741;

85 (b) S. D. Stranks, C. Weisspfennig, P. Parkinson, M. B. Johnston, L. M. Herz and R. J. Nicholas, Nano Lett., 2011, 11, 66; (c) A. J. Ferguson, J. L. Blackburn, J. M. Holt, N. Kopidakis, R. C. Tenent, T. M. Barnes, M. J. Heben and G. Rumbles, J. Phys. Chem. Lett., 2010, 1, 2406.

906 T. Umeyama, M. Fujita, N. Tezuka, N. Kadota, Y. Matano, K. Yoshida, S. Isoda and H. Imahori, J. Phys. Chem. C, 2007, 111, 11484.

7 (a) B. W. Smith, M. Monthioux and D. E. Luzzi, Nature, 1998, 396, 323; (b) H. Kataura, Y. Maniwa, T. Kodama, K. Kikuchi, K. Hirahara, K. Suenega, S. Iijima, S. Suzuki, Y. Achiba and W. Krätschmer, Synth. Met., 2001, 121, 1195.

8 J. Lee, H. Kim, S.-J. Kahng, G. Kim, Y.-W. Son, J. Ihm, H. Kato, Z. W. Wang, T. Okazaki, H. Shinohara and Y. Kuk, Nature, 2002, 415, 1005 .

1009 R. Hatakeyama, Y. F. Li, T. Y. Kato and T. Kaneko, Appl. Phys. Lett., 2010, 97, 013104.

10 N. Karousis, S. P. Economopoulos, Y. Iizumi, T. Okazaki, Z. Liu, K. Suenaga and N. Tagmatarchis, Chem. Commun., 2010, 46, 9110.

11 F. Chemg and A. Adronov, Chem. Mater., 2006, 18, 5389.

10512 H. Imahori, S. Kang, H. Hayashi, M. Haruta, H. Kurata, S. Isoda, S. E. Canton, Y. Infahsaeng, A. Kathiravan, T. Pascher, Pavel Chábera, A. P. Yartsev and V. Sundström, J. Phys. Chem. A, 2011, 115, 3679.

13 H. Kataura, Y. Kumazawa, Y. Maniwa, I. Umezu, S. Suzuki, Y. Ohtsuka, Y. Achiba, Synth. Met., 1999, 103, 2555.

11014 (a) D. J. Styers-Barnett, S. P. Ellison, C. Park, K. E. Wise and J. M. Papanikolas, J. Phys. Chem. A, 2005, 109, 289; (b) D. J. StyersBarnett, S. P. Ellison, B. P. Mehl, B. C. Westlake, R. L. House, C. Park, K. E. Wise and J. M. Papanikolas, J. Phys. Chem. C, 2008, 112, 4507.

11515 N. V. Tkachenko, H. Lemmetyinen, J. Sonoda, K. Ohkubo, T. Sato, H. Imahori and S. Fukuzumi, J. Phys. Chem. A, 2003, 107, 8834.

16 D. M. Guldi, H. Hungerbühler, E. Janata and K.-D. Asmus, J. Phys. Chem., 1993, 97, 11258. 